\title{
MORBIDITY PATTERN OF IHD IN SPOUSES OF IHD PATIENTS ATTENDING CARDIOLOGY OPD, S.N. HOSPITAL, AGRA MUKESH KUMAR ${ }^{\mathrm{a} 1}$ AND MANOJ KUMAR ${ }^{\mathrm{b}}$
}

additional CMO Ferozabad, UP, India

${ }^{\mathrm{b}} \mathrm{Sr}$ Consultant Distric Hospital Firozabad UP, India

\begin{abstract}
Ischaemic Heart Disease (IRD) is a major public health problem in industrial and urbanised countries where it has become a number one enemy of man. Material and Methods: The present study was carried out at S.N. Medical college \& Hospital, Agra. Duration of study was September 1988 to Oct 1989. Two hundred eighty six (42.4\%) males and 88 female! (13.0\%) were diagnosed as cases of Ischaemic heart Disease, among them $37(\mathbf{1 0 . 9 \% )}$ were those couples where both partners were diagnosed as cases of Ischaemic Heart Disease. Average age of husband and wife was 5 U.9 years and 44.2 years respectively. Cut of 286 males who came with Ischaemic Heart Disease or diagnosed as Ischaetdc Heart Disease have got average age of $51.74 \pm 6.56$ years while out of 88 women who had Ischaemic Heart Disease Wehere average age was $42.0 \pm 7.25$ years and average duration of Ischaemic Heart Disease among these cases was 1.45 years. It was concluded that triad of sedentariness, obesity and mental stress was common factor among 37 (10.8\%) couples where definite Ischaenic Heart Disease was present.
\end{abstract}

KEYWORDS: Ischaetdc Heart Disease, Hypertension, Obesity, Physical Activity

Ischaemic Heart Disease is defined as cardiac disability, acute or chronic, arising from reduction or arrest of blood supply to the myocardium in association with disease processes in the coronary arterial system (WHO, 1957). The expert Committee on Cardiovascular Diseases and Hypertension (WHO, 1959) accepted the term Coronary Heart Disease (CHD) as synonymous with IHD as defined above.

In some States in India, the hospital incidence increasing from 16.3 to $23.5 \%$ in five year duration, and death rate from IHD in hospitals varies between 5\% and $35 \%$ of cardiac disease.

I.H.D. causes disability or death in many who are still in the active ears of life and whose children are still young.

Its personal and social costs are profound both for the individuals and families involved and for the countries in which it is common.

Despite advances in treatment the mortality among survivors of an acute heart attack is still high-- around $10 \%$ in the first year and 5\% yearly thereafter, however $50 \%$ deaths occur within a month (WHO, 1982).

I.H.D. is a leading cause of death in man in industrialised societies at the age when their contribution to the society is most valuable (Fejfar, 1975). It is one of the major scourages of mankind today. In 1968, an ad-hoc committee of the World Health Organization expressed the opinion that Coronary Artery Disease was assuming the characteristics of a 'modern epidemic'.

Though infectious diseases and malnutrition still remain the major health problems, cardiovascular diseases have become an important cause of ill health in India. Ischaemic Heart Disease ranks second among the cardiovascular diseases next only to Rheumatic Heart Disease in urban communities (Bhatia, 1978).

I.H.D. accounts for approximately two-thirds of the total mortality from cardiovascular diseases in the age group 45-64 years (WHO, 1970). In the Netherlands, in $197445.7 \%$ of all deaths were due to cardiovascular diseases and $45.0 \%$ of these were from Coronary Heart Disease (Arntzonius, 1979).

Though it was considered that IHD is a problem of developed countries only, this statement does not hold true now because with urbanization, industrialization and with increase in life expectancy, it has percolated into the developing countries also. So much so that IHD has become a curse of industrialization and urbanization.

Most of the available information on the prevalence of IHD in India is based on hospital admissions. The proportion of CHD cases among all cardiac cased admitted to a hospital will depend on the number of cases of MED as well as the number of cases of other cardiac diseases, mainly. 
Important fectors associated with IHD as quoted by the various studies are Hyperlipidemia, Hypertension, Diabetes Mellitus, Smoking, Physical Inactivity, Obesity, Physical Inactivity, Obesity. This study was conducted with the objective: To find out morbidity pattern of IHD in spouses of IHD patients attending Cardiology OPD, S.N. Hospital, Agra.

\section{MATERIALS AND METHODS}

The present study was carried out at S.N. Medical college \& Hospital, Agra where the population of different cross section from and around Agra city representing rural/urban/different religions/castes and nearly all socioeconomic group came for the treatment of their cardiac ailment. Duration of study was September 1988 to Oct 1989.

After a intensive interviewing of these patients or spouses we switch on to BCC of spouses in search of IHD, then this strip of electro-cardiogram was thoroughly evaluated by experienced cardiologist of this institution and the results recorded on the pre-designed schedule.

The schedule covered among other factors, personal and economic status, age, education, occupation and area of living, addiction before and after the disease flourished and lastly the IHD profile which forced the patient to visit cardiology out patient department

Along with this test some other investigations like serum cholesterol and blood sugar were done to evaluate the full pattern of disease whenever required.

On the basis of population presuming as infinite a sample size of 337 was calculated for drawing the valid conclusions, statistically related to risk factors which plungs their spouses into CHD either by stress or by any other environmental factor.

In this study, because of multiplicity of variables and varying reports of CHD based on hospital admission, incidence was chosen to determine sample size indirectly.

Let $p$ be the incidence of IHD and $q$ be the no IHD happening. The standard error of $p$ is given by

$\sqrt{\frac{p q}{n}}$ where $\mathrm{n}$ is the sample size, The sample size $\mathrm{n}$ to be found out of the restrictions. :

1. The investigator allows an error of $20 \%$ of the incidence rate (6-23\%).

2. The investigator wishes to be correct in his estimate in 95 out of 100 attempts (safety factor 5\% \pm standard error attachment is set at 2 standard error distance, at which the chances are 20 to 1 against exceeding that range of error).

Hence

$$
2 \sqrt{\frac{\mathrm{pq}}{\mathrm{n}}}=20 \text { percent of } \mathrm{p}
$$

i.e. $\quad 2 \sqrt{\frac{23 \times 77}{n}}=\frac{20 \times 23}{100}$

or $\mathrm{n}=334 \pm 3$ cases $=337$ cases.

\section{Taking Population as Infinite}

There 337 IHD cases will be required to draw valid conclusion and inference, by allowing an error of $20 \%$ of the above rate (6-23\%) and on the basis where the investigator wishes to be correct in the estimate in 95 out of 100 attempts.

\section{Statistical Analysis}

Editing and coding of questionnaires were done The data were transferred to D.C.M. microsystem-1121 of statistical unit of the social and preventive medicine department of S.N. Medical College, Agra for analysis

\section{RESULTS}

This study is based on information collected by direct personal interview of 337 patients and their spouses thus making the total number 674 . All of them belongs to Agra district or nearby town or Villages. On analysis of these individuals we got 300 people out of 674who were not having IHD and 374 were those who presented to us with I.H.D. Out of these 374 cases, 286 were male and 88 were female and 37 couples were those who presented to us as a case of IHD either as proved cases or we diagnosed them as a case of IHD incidentally. Study of these cases after interviewing ECG, revealed the following observations: 
Table 1: Case of I.H.D.

\begin{tabular}{|c|c|c|c|c|}
\hline & Male & Female & Total & \% \\
\hline Angina & 27 & 27 & 54 & 8.0 \\
\hline Coronary & 20 & 37 & 57 & 8.4 \\
\hline Insufficiency N.I. & 222 & 7 & 229 & 33.9 \\
\hline Arrhythmia & 14 & 17 & 31 & 4.5 \\
\hline LVF & 3 & - & 3 & 0.4 \\
\hline Total & 286 & 88 & & \\
\hline None & 51 & 249 & 300 & 100 \\
\hline Total & 337 & 337 & 674 & \\
\hline
\end{tabular}

It has been observed that $55.5 \%$ in present study were diagnosed as cases of IHD, while $44.5 \%$ did not show any evidence of IHD. Out of these cases $42.4 \$$ (286) were males while $13.0 \%$ (86) were female. Majority (33.9\%) of patient were presented as cases of M.I. while only $0.4 \%$ (3) were diagnosed as cases of LVL in present study, simultaneously angina and coronary insufficiency cases were also presented in considerable number i.e. $(8.0 \%$ and $8.4 \%$ respectively).

Out of 337 couples, $17.7 \%$ were known to cases of hypertension. Out of these 337 couples, 150 (44.5\%) couples were quite right and none of them have any evidence of hypertension, while 157 (55.5\%) couples were having IHD and they were classified according to blood pressure in following three groups $65.5 \%$ were normotensive, $28.8 \%$ were hypertensive while rest $5.0 \%$ were hypotensive among male counterparts, while females were $47.0 \%$ normotensive, $35.0 \%$ were hypertensive and only $17.9 \%$ were belonging to hypotensive group.

Cut of $16 \%$ (108) cases who had systolic blood pressure raise $71.2 \%$ were presented as M.I. while $15.7 \%$ were of angina and $13.1 \%$ were diagnosed as arrhythmia cases. In 21 cases of systolic hypotensive, group angina coronary insufficiency and M.I. shared the equal proportion i.e. $33.3 \%$ while cases with diastolic blood pressure raised $77 \%$ were cases of MI and 5.3 diagnoseed as cases of coronary insufficiency while $16.3 \%$ were anginal in character. On further analysis 67 cases with low diastolic at extermes higher and lower percentage were of MI and LVF with $47.7 \%$ and $4.7 \%$ respectively. All above findings were proved significant statistically except for $Z$ between diastolic hypotensive $\mathrm{Vs}$ diastolic hypertensive where $\mathrm{Z}=$ $1.6 ; \mathrm{p}=>.05$.

Table 2: Obesity with I.H.D.

\begin{tabular}{|c|c|c|c|c|}
\hline IHD Presentation & Obese & Non-obese & Total & \% \\
\hline Angina & 10 & 44 & 54 & 8.0 \\
\hline Coronary & 3 & 54 & 57 & 8.5 \\
\hline Insufficiency M.I. & 57 & 172 & 229 & 34.0 \\
\hline Arrhythmia & 8 & 23 & 31 & 4.5 \\
\hline LVF & - & 3 & 3 & 0.5 \\
\hline Total & 33 & 267 & 300 & 44.5 \\
\hline None & 111 & 563 & 674 & 100 \\
\hline Percentage & 16.5 & 83.5 & & \\
\hline \multicolumn{7}{|c|}{$\mathrm{X}^{2}=10.9$, d.f. $=3 ; \mathrm{p}<0.5$} \\
\end{tabular}

It was found that those couples who both had IHD, all 37 makes were diagnosed as cases of Myocardial infarction and out of these $13.5 \%$ were those whose diastolic as well as systolic pressure was raised, while among female counterparts only $5.4 \%$ had raised systolic pressure and none of them had evidence of raised diastolic pressure. However these findings were not proved significant later on statistically where $Z=<2 ; p=>.50$.

Table 2 depicts that considerable number (57) of M.I. were obses i.e. $24.8 \%$ although $75.2 \%$ of MI cases were non-obese. Patient having coronary insufficiency were least obese, while patient having arrhythmia were obese in 
proportion of $25.8 \%$ and approximately equalizes the proportion of MI (24.8\%). Out of those couples who both had IHD $22.9 \%$ were obese. Among than $35.1 \%$ were male and $10.8 \%$ were female, while $64.9 \%$ were male and $89.9 \%$ remales were non-obese in present study but these findings could not be proved significant on statistical analysis.

Out of the IHD cases majority $(63.0 \%)$ were not addicted to any sort of alcohol smoking etc. Even $52.9 \%$ of these groups were having IHD while $47.0 \%$ of these were not having IHD.

249 (36.9\%) were cases who were addicted, out of these patients $32.4 \%$ were alcoholic, $25.6 \%$ were tobacco chewer and $30.9 \%$ were smoker. Out of addicted cases $3.6 \%$ were taking it for $2-5$ years and $27.3 \%$ were smoking for last 5 years or more than 5 years, while $11.6 \%$ were taking Pan masala and $9.2 \%$ were those cases who had addiction in the form of combination (cigarette smoking + tobacco chewing + alcoholic etc.).

Average duration of these addicted cases when calculated was $4.3+0.58$ years and $\mathrm{X}^{2}$ was significant for alcohol and smoking in present study where values of $X^{2}$ for alcohol was 12.48 , d.f. $1, \mathrm{p}=<.05$, and values of $\mathrm{X}^{2}$ for smoking was 33.54, d.f. $=1 ; \mathrm{p}=<.05$.
Mostly people in our study group were engaged in moderate day to day activity. This was also combined with hard activity concurrently in cases of male counterparts, while female were not showing any hard day to day activity particularly among IHD group. Sedentary habits are more prevalent among women $28.0 \%$ than man who were only $6.6 \%$ among disease group. According to nature of work out of the 337 couples majority were doing the moderate physical activity (52.5\% male, $56.7 \%$ female). Among the males a very small percentage (5.6) was of sedentary worker and all of them had some form of IHD, out of these majority (84.2\%) had the MI, while amongst the female counterparts the percentage of sedentary workers was $38.2 \%$, and out of them only $24.4 \%$ had some form of IHD, majority presenting with coronary insufficiency and there was significant relationship i.e. $\mathrm{X}^{2}=5.86$, d.f. $=.1, \mathrm{p}<$ .05 .

Among moderately working males $78.3 \%$ and the IHD and the leading cause of presentation being MI in $70.62 \%$ cases.

Out of those ocuples who both were having IHD $(18.9 \%)$ women were of sedentary habits and only $10.8 \%$ men were of this habit while rest of the percentage belongs to moderate and hard variety.

Table 3: Diet with I.H.D.

\begin{tabular}{|c|c|c|c|c|c|c|}
\hline \multirow{2}{*}{ Dietary habits } & \multicolumn{2}{|c|}{ IHD (yes) } & \multicolumn{2}{|c|}{ IHD (no) } & \multirow{2}{*}{ Total } & \multirow{2}{*}{$\%$} \\
\hline & $\mathrm{H}$ & $\mathrm{W}$ & $\mathrm{H}$ & $\mathrm{W}$ & & \\
\hline Vegetarian & 57 & 20 & 10 & 78 & 165 & 24.5 \\
\hline Eggitarian & 73 & 18 & 20 & 54 & 165 & 24.5 \\
\hline Non vegetarian & 156 & 50 & 33 & 105 & 344 & 51.0 \\
\hline Total & \multicolumn{2}{|c|}{374} & \multicolumn{2}{|c|}{300} & \multicolumn{2}{|c|}{100} \\
\hline Percentage & \multicolumn{2}{|c|}{55} & \multicolumn{2}{|c|}{45} & & \\
\hline
\end{tabular}

Table 3 shows that majority of cases were nonvegetarian and prevalence of IHD was also higher in the ssame group, which nearly half percent were belong to Eggitarian and vegetarian combinedly, but most of nonvegetarians were obviously eggitarian also. On applying $\mathrm{X}^{2}$ test for husband results were insignificant statistically (X2 = 1.15 , d.f. $=2, p>.05)$ and for women results were significant $\left(X^{2}=4.86\right.$, d.f. $\left.=2, p<.05\right)$
Similarly those couples, who both presenting with IHD were non-vegetarian (78.4\%) and vegetarian + aggitration were $10.8 \%$ each in proportion.

\section{DISCUSSION}

Retrospective studies have demonstrated the association between risk factors and IHD while prospective studies have shown the possibility, of predicting morbidity and mortality, including atherosclerotic sudden death (Friedman et a1., 1975). Risk factors are difficult to change but insiite of critic some results an: encouraging and 
suggest that risk factor detection is advisable as early as possible (Goldstein et al.,, 1976). Lany primary prevention trials have stiown some progress in different -Darts of the world. In secondary prevention the problem of identifying and treating individuals susceptible to atherosclerotic sudden death has not yet yielded results (Doyle, 1975).

\section{HYPERTENSION}

Very few reports are available in which the prevalence of hypertension has been studied oh the basis of total population survey. The importance of such studies lies in the fact that only in this manner true estimate can be obtained of the prevalence of hypertension in different populations.

The prevalence of hypertension as observed in the present study (17.7\%) is consistent with $17.3 \%$ by Neuman et al., (1979), $18.7 \%$ by Teeng (1967) in fishing population.

The prevalence in present study is much higher than the reported $0.17 \%$ and 2.5$) 2$ by Pacimavati and Gupta (1959) in low and high socioeconomic groups respectively,

Table 4: Various Studies Showing Following Prevalence in India

\begin{tabular}{|c|c|c|c|c|c|c|c|c|}
\hline \multirow{3}{*}{ Author } & \multirow{3}{*}{ Year } & \multicolumn{7}{|c|}{ Prevalence of IHD } \\
\hline & & \multirow{2}{*}{$\begin{array}{c}\text { Age in } \\
\text { year }\end{array}$} & \multicolumn{3}{|c|}{ Males } & \multicolumn{3}{|c|}{ Females } \\
\hline & & & Probable & Suspect & Total & Probable & Suspect & Total \\
\hline Sarvothani \& Berry & 1968 & $>30$ & $6.54 \%$ & $3.88 \%$ & $10.42 \%$ & $4.78 \%$ & $11.51 \%$ & $16.29 \%$ \\
\hline Dewan et al., 1 & 1974 & $>30$ & $1.7 \%$ & $0.57 \%$ & $2.27 \%$ & $1.26 \%$ & $0.47 \%$ & $1.73 \%$ \\
\hline Jackson et al., & 1980 & $>18$ & $4.2 \%$ & $0.00 \%$ & $4.3 \%$ & $9.1 \%$ & $7.6 \%$ & $14.7 \%$ \\
\hline
\end{tabular}

The prevalence of hyperterision in the present study is slightly lower as compared to $21.5 \%$ by Servotham and Berry (1968) and $20.1 \%$ by Schoenberger et al., (1972).

The present study revealed that the males had a slightly higher prevalence of hypertension as compared to females. The prevalence of hypertension in males increased till the age group of 50-59 years and sharp decline was observed after the age of 60 years in the present study, while Gupta et al., (1978) and Gupta et al., (1977) found linear rise in proportion, hypertensive's in males with the increasing age.

The prevalence' of obesity was 11 . in the present study as compared to $33.4 \%$ in Gupta et al., (1977), Dewan et al., (1974) 18.35\%; Gupta et al.,(1978) $11.5 \%$ and 40.3; in the subjects with relative weight $>1.10$ and 19.3 with relative weight $>1.20$ in Neuman et al., (1979). As the criteria for obesity were different and also the age groups varied from study to study,

The prevalence of sedentariness in the present study i.e. $21.95 \%$ was less as compared to $44.8 \%$ reported by Neuman et al., (1979) and slightly higher as compared to $20.81 \%$ by Gupta et al., (1977) but lower to $24.10 \%$ by Gupta et al., (1978) and 25.66-A by Dewan et al., (1974). The higher prevalence in other studies carried out in India could be because in addition to occupational activity, non occupational activity (Leisure Activity) might have been taken into consideration while grading the respondents according to physical activity.

The females were found to be more sedentary than males in all these studies and the differences was highly statistically significant in the present study and in to study by Neuman et al., (1979).

\section{CONCLUSION}

Thus, it can safely concluded that triad of sedentariness, obesity and mental stress was common factor among 37 (10.8\%) couples where definite Ischaenic Heart Disease was present, Therefore morbidity of Ischaemic Heart Disease among spouses of Ischemic Heart Disease cases observed was $5.4 \%$ only.

The Ischnemic heart Disease was more prevalent among highly educated higher socioeconomic groups and in those who are passing through considerable strain or those who have coronary prone personality.

\section{REFERENCES}

Arntzenius A.C., 1997. Environmental factors in the development of Atherosclerosis cited by Ritsm in Atherosclerosis Excerpta Media, Amsterdam, Oxford, p.4. 
Bhatia B.B. and Jain C.C., 1953. Corpulmonale: Indian Heart Jr., 5: 117.

Doyle J.T., Dawber T.R., Kannel W.B., Kinch S.H. and Kahn H.A., 1964. The relationship of cigarette smoking to coronary heart disease. The second report of the combined experience of the Albany, New Yorkl and Framingham, Mass. Studies Jr. of American Medical, Association, 190: 886.

Dewan B.D., Malhotra K.C. and Gupta S.P., 1974. Epidemiological study of coronary heart disease in rural community in haryana : Indian Heart Jr., 26(2): 68 .

Friedman G.D., Klatsky A.L. and Siegelaub A.B., 1975. Predictors of sudden cardiac death; Circulation, 52(Supplement III): 164.

Goldstein J.I., Albers J.J., Mazarad W.R., Schrott H.G., Drerman E.L. and fotulsy A.G., 1973. Genetic and medical significance of neonatal hyperlipidemia; Journal of clinical investigation, 52: 35 a, 1973.

Gupta S.P., Stwach S.B. and Moda V.K., 1978. Epidemiology of hyper-tension based on total community survey in the urban population of Haryana; Indian Heart Jr., 30(6): 315.

Gupta S.P. and Garg P., 1977. Smoking and coronary heart diseases- A comparative evaluation of cigarette and bidi smoking; Jr. of Association of Physicians of India, 25(12): 859.

Jackson R.L., Morrisett J.D. and Gotto A.M., Lipoproteins and lipid transport; structural and functional concepts in Hyperlipidaemia, Rifkind BM and levy R.I. (Editors) Gurne and Stratton New York, Sen Fransisco London.

Neuman J., Neurnan P.D., Valero E. and Lindental D., 1979. Epidetniology of coronary heart disease risk factors in a free living population; Preventive Medicine; 8: 1445.

Pactaavati S., 1958. A five year study of Heart Disease in Delhi, Indian Heart Jr., 10: 33.

Sarvothani D.G. and Berry J.N., 1968. Prevalence of coronary heart disease in an urban population in Northern India. Circulation, 37: 939.

Schoenberger J.A., Stamler J.A., Stamler J. and Shekella S., 1972. Current status of hyper tension control in an industrial population; Jr. of American Medical issociation, 222(5): 559.

Teeng W.P., 1967. Blood pressure and hypertension in an agricultural and a $\mathrm{ft}$ shing population in Taiwan 'American Jr. cf Epidemiology; 86(3): 513.

W.H.O., 1957. Atherosclerosis and ischaeriiic heart diseases; Technical Reicrt series No.117.

W.H.O., 1959. Hypertension and coronary heart disease; classification and criteria for epidemic logical studies; Technical Report SeriesNo.168.

W.H.O., 1982. Prevention of CHD. Report of WHO expert Committee, TRS 678, p.8.

W.H.O., 1970. The pathological diagnosis of Acute Ischaemic Heart Disease; Technical Report Series No. 441. 